\title{
BMJ Open New episodes of musculoskeletal conditions among employed people in Norway, sickness certification and return to work: a multiregister-based cohort study from primary care
}

\author{
Sturla Gjesdal, ${ }^{1}$ Tor Helge Holmaas, ${ }^{2}$ Karin Monstad, ${ }^{2}$ Øystein Hetlevik ${ }^{1}$
}

To cite: Gjesdal S, Holmaas TH, Monstad K, et al. New episodes of musculoskeletal conditions among employed people in Norway, sickness certification and return to work: a multiregister-based cohort study from primary care. BMJ Open 2018;8:e017543. doi:10.1136/ bmjopen-2017-017543

- Prepublication history and additional material for this paper are available online. To view these files, please visit the journal online (http://dx.doi. org/10.1136/bmjopen-2017017543).

Received 22 May 2017 Revised 1 November 2017 Accepted 3 November 2017

Check for updates

${ }^{1}$ Department of Global Health and Primary Care, University of Bergen, Bergen, Norway

${ }^{2}$ UNI Research Rokkan Centre, Bergen, Norway

Correspondence to Professor Sturla Gjesdal; sturla.gjesdal@uib.no

\section{ABSTRACT}

Objectives To identify new cases of musculoskeletal (MSK) disorders among employed people presenting in Norwegian primary care in 2012, frequency of sickness certification and length of sick leave. To identify patient-, diagnosis- and GP-related predictors of sickness certification, prolonged sick leave and return to work (RTW).

Methods An observational multiregister-based cohort study covering all employed persons in Norway(1 176681 women and 1330082 men) based on claims data from all regular GPs merged with individual sociodemographic data from public registers was performed. Participants were employed patients without any GP consultation during the previous 3 months who consulted a GP with a diagnosis of a MSK condition. Those not on sick leave and with a known GP affiliation were included in the analyses. Outcomes were incidence, proportion sickness certified and proportion on sick leave after 16 days, according to the diagnosis, ORs with 95\% Cls for sickness certified and for sick leave exceeding 16 days and HRs with $95 \%$ Cls for RTW.

Results One-year incidence of MSK episodes was 159/1000 among employed women and 156/1000 among employed men. $27.1 \%$ of the women and $28.2 \%$ of the men were sickness certified in the initial consultation. After 16 days, $10.5 \%$ of women and $9.9 \%$ of men were still on sick leave. Upper limb problems were most frequent. After adjustments, medium/high education predicted a lower risk of absence from work due to sickness and rapid RTW after 16 days. Back pain, fractures and female gender carried a higher risk of sickness certification but faster RTW. Older age was associated with less initial certification, more sick leave exceeding 16 days and slower RTW. Male patients with male GPs had a lower risk of sickness absence, which was similar to patients with GPs born in Norway and GPs with many patients. After 16 days, GP variables had no effect on RTW. Conclusion Upper limb problems and GPs as stakeholders in 'the inclusive workplace' strategy need more attention.

\section{INTRODUCTION}

Musculoskeletal (MSK) disorders, together with common mental disorders, are the main cause of sick leave and disability benefits, ${ }^{12}$ and related societal costs are high. ${ }^{3}$
Strengths and limitations of this study

- To our knowledge, this is the first nationwide inception study investigating the full spectrum of MSK conditions in the total employed population presenting in primary care.

- Complete patient, diagnosis and GP data were used to identify the incidence of MSK disorders and predictors of sickness certification, prolonged sick leave and return to work

- Self-reported and clinical data from patients and data on workplace conditions were lacking, reducing the scope of possible predictors of sick leave and return to work.

Approximately $10 \%$ of absence from work due to sickness in the UK is related to back pain and $10-12 \%$ to other MSK conditions, ${ }^{4}$ whereas in Norway $30 \%$ are caused by MSK conditions, $7-8 \%$ by back pain and $7-8 \%$ by neck and arm problems. ${ }^{5}$ A third of longterm retirement cases in both the UK and the Nordic countries are caused by MSK disorders, and several studies have investigated predictors for chronicity among patients on sick leave with MSK conditions. ${ }^{6-9}$ According to a recent Dutch study of back pain, ${ }^{10}$ lost productivity and short-term sick leave account for $48 \%$ of the societal costs, permanent disability accounts for $39 \%$ and only $13 \%$ are direct costs, mainly for healthcare.

Usually a medical certificate is needed to obtain compensation for absence due to sickness, following a self-certification period. In many countries GPs are the main providers of sickness certificates, and in Norway $40 \%$ of the GPs report to have more than 20 sickness certification consultations every week. ${ }^{11}$ Thus, GPs have a key role in managing MSK conditions, ${ }^{1213}$ but the full magnitude of this challenge is unknown. Moreover, the role of the certifying 
doctor is seldom acknowledged when determinants of sick leave and return to work (RTW) are investigated. ${ }^{7}$

Inception studies ${ }^{714}$ based on new cases identified directly by a doctor ${ }^{6} 15$ or including cases following a 'washout' period ${ }^{16}$ are the preferred design for studies of predictors of sick leave and RTW. ${ }^{7}$ Most prospective studies of workers with MSK problems include patients out of work for at least 4-6 weeks, ${ }^{717}$ and investigations of the start of absences and short-term leave are scarce. ${ }^{18}$ The burden of MSK conditions is often assessed in population surveys ${ }^{19-21}$ where the employment status of respondents is not ascertained but prevalence data from the working age groups is often reported.

However, in countries like Norway, Denmark, the Netherlands, UK, Canada and Australia where the health services are based on the gatekeeper model (NHS model), the first point of care for people with troublesome MSK conditions is usually the general practitioner (GP) ${ }^{22} \mathrm{~A}$ recent Canadian study found that $80 \%$ of those seeking outpatient medical care for MSK conditions used primary care. $^{23}$ The present paper contributes to an emerging literature of population-based studies based on information from primary care, ${ }^{24}$ using either routine data ${ }^{23}$ or investigations like the Dutch National GP Survey ${ }^{1525}$ or data from research networks. ${ }^{1426}$ The aims of the present study were:

- To identify all employed people consulting a GP for a new MSK episode in Norway during 1 year, estimating the 1-year incidence of different MSK disorders.

- To measure the proportion who were sickness certified in these consultations.

- To measure the proportion on sick leave exceeding 16 days.

- To measure the length of absence due to sickness lasting more than 16 days and the proportion staying on sick leave for 1 year according to diagnoses.

- To identify predictors of sickness certification, sick leave exceeding 16 days and length of absence.

Possible gender differences were assessed in all analyses.

\section{METHODS}

\section{Study design and data sources}

A retrospective multiregister-based cohort study was performed with data from publicly-funded GPs in Norway during 2012. Since 2001, all legal residents in Norway can select a regular GP (RGP) who is state funded by a combination of copayment, capitation and fee-for-service. After each consultation the GPs send an invoice to the National Health Economics Administration (HELFO), specifying the main medical reason for attendance based on the International Classification of Primary Care (ICPC), ${ }^{27}$ procedures performed in the consultation and the personal identity number of the patient. Data from all invoices are entered into the Register of Control and Payment of Healthcare Reimbursements (KUHR), which researchers can use in anonymised form with permission from the Data
Inspectorate. HELFO also holds a register of the RGPs, including information about age, gender, specialty status and the identity numbers of the patients on their list. Complete person-based data on state-funded absence due to sickness (17-365 days), including a diagnosis based on the ICPC, is held by the national insurance services and is also available for research.

\section{Population at risk}

The population comprised legal residents in Norway below the age of 67 with an income from work exceeding NOK 40157 (EUR 5425) at 1 January 2012 (n=1 176681 women and $1330082 \mathrm{men}$ ).

\section{Participants and follow-up}

To identify new cases of MSK conditions, employed patients who had not consulted a GP during the previous 3 months (the washout period) consulting with a MSK disorder as the main diagnosis during 2012 were included in the study $(n=394781)$. Only the first episode per patient was included. Patients already on sick leave were excluded when rates of sickness certification were

Employed population below 67 years 01.01 .2012 $(1,176,681$ women and $1,330,082$ men $)$

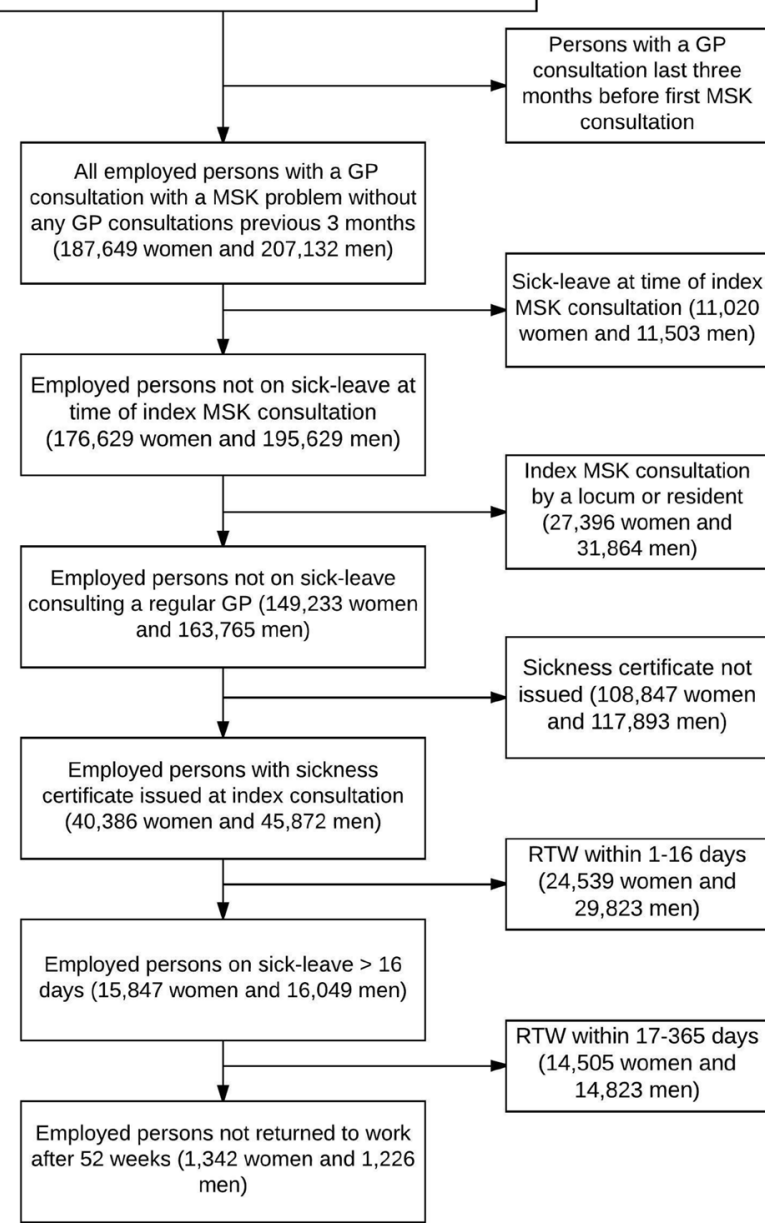

Figure 1 Flowchart showing the study design: population at risk and different study samples. MSK, musculoskeletal; RTW, return to work. 
Table 1 Characteristics of study population: employed individuals not on sick leave, consulting a general practitioner (GP) with a new musculoskeletal (MSK) episode in 2012 and characteristics of sample with known GP affiliation

\begin{tabular}{|c|c|c|c|c|}
\hline \multirow[b]{2}{*}{ Consultations according to ICPC codes* } & \multicolumn{2}{|c|}{$\begin{array}{l}\text { Study population } \\
(\mathrm{n}=372258)\end{array}$} & \multicolumn{2}{|c|}{$\begin{array}{l}\text { Sample with known GP } \\
\qquad(n=312998)\end{array}$} \\
\hline & Women & Men & Women & Men \\
\hline Back problem & $18 \%$ & $22 \%$ & $18 \%$ & $22 \%$ \\
\hline Neck problem & $8 \%$ & $5 \%$ & $8 \%$ & $5 \%$ \\
\hline Lower limb & $18 \%$ & $19 \%$ & $18 \%$ & $19 \%$ \\
\hline Upper limb & $27 \%$ & $28 \%$ & $27 \%$ & $28 \%$ \\
\hline Fractures & $7 \%$ & $12 \%$ & $7 \%$ & $11 \%$ \\
\hline Widespread myalgia & $11 \%$ & $6 \%$ & $11 \%$ & $6 \%$ \\
\hline Rheumatoid & $1 \%$ & $1 \%$ & $1 \%$ & $1 \%$ \\
\hline Osteoarthrosis & $3 \%$ & $2 \%$ & $3 \%$ & $2 \%$ \\
\hline Other MSK conditions & $6 \%$ & $5 \%$ & $7 \%$ & $6 \%$ \\
\hline \multicolumn{5}{|l|}{ Patient characteristics } \\
\hline Patient age, mean (SD) & $42.9(12.3)$ & $41.6(12.6)$ & $43.2(12.3)$ & $41.8(12.5)$ \\
\hline \multicolumn{5}{|l|}{ Education level } \\
\hline Basic education & $20 \%$ & $25 \%$ & $20 \%$ & $24 \%$ \\
\hline Upper secondary education & $42 \%$ & $50 \%$ & $42 \%$ & $50 \%$ \\
\hline Higher education & $38 \%$ & $25 \%$ & $38 \%$ & $26 \%$ \\
\hline Labour income in $100000 \mathrm{NOK}, \dagger$ mean (SD) & $3.7(1.9)$ & $5.0(4.0)$ & $3.7(2.0)$ & $5.1(4.0)$ \\
\hline \multicolumn{5}{|l|}{ Marital status (reference never married) } \\
\hline Unmarried & $35 \%$ & $43 \%$ & $34 \%$ & $42 \%$ \\
\hline Married & $49 \%$ & $46 \%$ & $50 \%$ & $47 \%$ \\
\hline Divorced or widow(er) & $16 \%$ & $11 \%$ & $16 \%$ & $11 \%$ \\
\hline Years on regular GP's list, mean (SD) & $6.4(4.1)$ & $6.4(4.1)$ & $6.5(4.1)$ & $6.4(4.1)$ \\
\hline \multicolumn{5}{|l|}{ GP characteristics $(n=4031)$} \\
\hline Male & & & $62 \%$ & $77 \%$ \\
\hline Age, mean (SD) & & & $49.1(10.5)$ & $49.2(10.7)$ \\
\hline Specialist in family medicine & & & $63 \%$ & $62 \%$ \\
\hline Born in Norway & & & $69 \%$ & $67 \%$ \\
\hline List size, mean (SD) & & & $1273(397)$ & $1288(408)$ \\
\hline $\mathrm{N}$ & 176599 & 195560 & 149233 & 163765 \\
\hline
\end{tabular}

*Diagnoses based on the ICPC.

†100 000 NOK (Norwegian kroners)=13570 Euro as of January 2012.

ICPC, International Classification of Primary Care.

estimated ( $n=372258$ ). Among the index consultations found in the KUHR database, $21 \%$ were carried out by locums or resident doctors. In order to investigate GP variables, only participants consulting one of the 4031 RGPs in the RGP database were included in the analyses $(n=312998)$. Participants still on sick leave after 16 days $(n=31$ 896) were followed further for 349 days in the sickness benefits register (see flowchart in figure 1).

\section{Outcomes}

- The first outcome was consulting a GP with a new episode of a MSK condition, used to calculate the 1-year incidence of different MSK conditions.
- The second outcome was receiving a sickness certificate in the index consultation. Having the code L1 in the invoice from this consultation indicates sickness certification.

- The third outcome was being in the national insurance services' sickness benefits register 17 days after the index consultation. In Norway, employers pay sickness benefits for the first 16 days; thereafter statefunded sickness benefits are paid for a maximum of 349 days.

- The fourth outcome was (time to) termination of sickness absence benefits. Most of those leaving the sickness benefits register before the maximum length of 
1 year return to work, so this was considered a 'proxy' for RTW.

\section{Independent variables}

The following independent variables were examined as possible predictors for the three outcomes:

- The main diagnosis obtained from the GPs' invoices. The MSK diagnoses were divided into nine mutually exclusive groups based on the ICPC code used by the GPs: four groups related to body location (back, neck, upper extremities and lower extremities) and five groups related to type of disease (fractures/injuries, osteoarthritis, widespread myalgia, inflammatory rheumatism and 'other'). The groupings of ICPC codes are shown in table $\mathrm{X}$ in the online data supplement). In the logistic regressions, the largest group (upper limb) was used as reference.

- GP characteristics (age, gender, specialty status), patient list length (per 100) and whether the list was open for new patients were obtained from the RGP register.

- Length of time (years) the patient had 'belonged to' the RGP was obtained from the RGP register.

- Information on the patients' age and gender was obtained from the Central Population Register. Age was used as a continuous variable and presented as age/10 in statistical analyses.

- Annual labour income was obtained from the tax register and presented as NOK/100 000.

- Highest completed education was obtained from the national educational register and categorised into basic, secondary and high (university/college).

The registers are considered as complete and valid. After permission from the Data Inspectorate and the register owners, the data were merged by Statistics Norway.

\section{Statistical analyses}

The characteristics of all participants and the sample used in logistic regressions are shown in table 1.

Logistic regression was used to assess associations between independent variables and being sickness certified initially and being on sick leave for $>16$ days. Odds ratios (ORs) for the full sample (not shown in tables) and for men and women were estimated. For those on sick leave exceeding 16 days, time to termination of sickness benefits was ascertained and survival curves were fitted (figure 2). 'Risk' for termination of sickness benefits was assessed using Cox proportional hazards analysis. Hazard ratios (HRs) were estimated for the full sample and separately by gender, with the same independent variables. HR $>1$ indicates a rapid RTW. GP variables had no effects on HRs and are not shown in the tables. Because of the large dataset, a significance level of $\mathrm{P}<0.01$ was chosen for all analyses; $\mathrm{P}$ values $<0.05$ and $<0.001$ are also reported in the tables. The statistical programme Stata Version 14 (StataCorp, College Station, Texas, USA) was used.

\section{RESULTS}

A total of 187649 employed women and 207132 employed men consulted a RGP with a new MSK episode in 2012 (16.0\% of women and $15.6 \%$ of men). Among both genders the incidence of upper limb problems was highest $(4.3 \%$ and $4.4 \%$ for women and men, respectively), compared with $2.8 \%$ and $3.4 \%$ for back disorders (table 2). Neck problems (1.2\% vs $0.8 \%$ ) and widespread myalgia $(1.7 \%$ vs $0.9 \%)$ were more frequent among women, whereas men more often had fractures/injuries $(1.2 \%$ vs $1.9 \%)$. Table 2 also shows the proportions (\%) who were sickness certified and who stayed on sick leave for $>16$ days among those not on sick leave at baseline $(\mathrm{n}=176629$ women and $\mathrm{n}=195629$ men), according to

Table 2 One-year incidence of new general practitioner (GP) consultations with a musculoskeletal (MSK) diagnosis among employed people in Norway during 2012 and percentage sickness certified and percentage remaining on sick leave for $>16$ days among those not on sick leave at baseline ( $n=176599$ women and 195560 men)

\begin{tabular}{|c|c|c|c|c|c|c|}
\hline & \multicolumn{2}{|c|}{ Consult/1000/year } & \multicolumn{2}{|c|}{ Sickness certified (\%) } & \multicolumn{2}{|c|}{ Sick leave $>16$ days $(\%)$} \\
\hline & Women & Men & Women & Men & Women & Men \\
\hline Back problems & 28.4 & 34.1 & 40.3 & 44.3 & 13.3 & 14.1 \\
\hline Neck problems & 12.3 & 7.7 & 35.0 & 31.3 & 14.4 & 11.6 \\
\hline Upper limb & 43.4 & 44.0 & 27.8 & 23.9 & 11.6 & 9.3 \\
\hline Lower limb & 28.8 & 29.3 & 14.8 & 17.6 & 5.1 & 6.0 \\
\hline Fractures & 11.8 & 18.5 & 36.1 & 36.1 & 13.0 & 12.5 \\
\hline Widespread myalgia & 8.5 & 8.3 & 24.1 & 21.1 & 10.7 & 7.2 \\
\hline Osteoarthrosis & 5.3 & 3.5 & 18.8 & 19.1 & 10.4 & 10.4 \\
\hline Rheumatoid dis & 2.2 & 1.7 & 23.4 & 21.4 & 11.0 & 10.1 \\
\hline Other MSK & 10.2 & 8.4 & 12.6 & 16.4 & 5.0 & 5.8 \\
\hline Total & 159.5 & 155.7 & 27.1 & 28.2 & 10.5 & 9.9 \\
\hline Population at risk & 1176681 & 1330082 & & & & \\
\hline
\end{tabular}




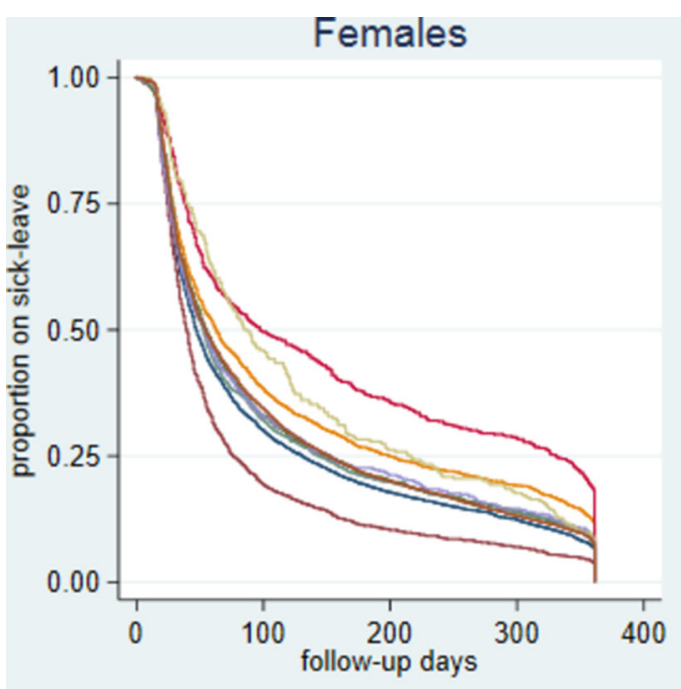

Males
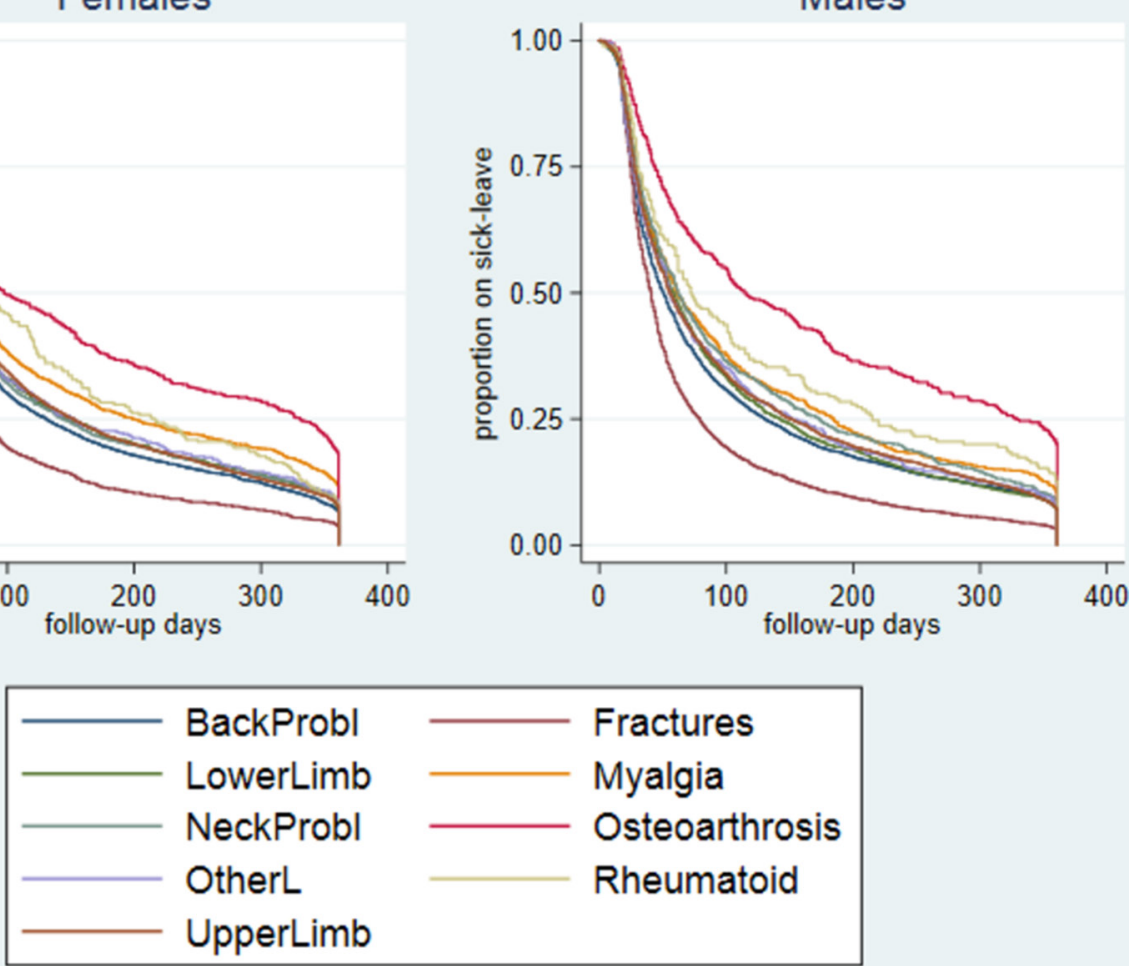

Figure 2 Survival curves showing data for follow-up from 17 to 365 days of sick leave according to gender and diagnosis. Date for termination of sickness absence benefits is the outcome event $(n=15465$ men and $n=15437$ women on sick leave $>16$ days).

diagnoses. Among women, $27.1 \%$ were sickness certified initially compared with $28.2 \%$ of men. Among patients with back problems $40.3 \%$ of women and $44.3 \%$ of men were sickness certified. The corresponding figures for upper limb problems were $27.8 \%$ and $23.9 \%$, respectively. After 16 days, $10.5 \%$ of women and $9.9 \%$ of men (15047 women and 16049 men) were found in the sickness benefits register and were followed with termination of benefits as the outcome event. The percentages for back pain were $13.3 \%$ and $14.1 \%$ and for upper limb problems $11.6 \%$ and $9.3 \%$. A total of 1342 women and 1226 men stayed on sick leave for the maximum duration of 1 year.

The average length of absence due to sickness varied according to diagnosis. The mean length was 101 days for back disorders, 110 days for upper limb conditions and 164 days for osteoarthrosis. Figure 2 shows the duration of sick leave ranging from 17 to 385 days, according to diagnosis and gender.

In the full sample, $9 \%$ of women and $8 \%$ of men remained on sick leave for the maximum of 1 year, $12 \%$ of those with widespread myalgia and $20 \%$ with osteoarthrosis. Mean duration of absence from work due to sickness and proportion staying on sick leave for 1 year according to diagnosis are shown in table XX in the online data supplement.

\section{Predictors of initial sickness certification and sick leave exceeding 16 days}

The risk of initial sickness certification was slightly lower for men than for women (OR 0.97 (95\% CI 0.95 to
$1.00), \mathrm{P}<0.01$ ), not shown in tables. Table 3 shows ORs with $95 \%$ CIs for initial sickness certification. Higher age reduced the risk for men, as did medium and higher education for both genders. Divorcees had a higher risk than married and never-married individuals. Patients with back pain, neck pain or fractures/injuries had a higher risk of sickness certification than those with upper limb problems. Having a male GP and a long GP relationship reduced the risk of sickness certification for men, whereas a GP born in Norway had the same effect for both genders.

Table 3 also shows predictors for staying on sick leave for $>16$ days. Men had a lower risk (OR $0.88(95 \%$ CI 0.86 to 0.90$), \mathrm{P}<0.005$ ) (not shown). Higher age and being divorced increased the risk whereas medium or high education carried a lower risk. The income variable had opposite effect among men and women. Patients with back problems, neck problems and injuries had a higher risk for staying on sick leave for $>16$ days than those with upper limb problems. Male patients with male GPs or with GPs born in Norway had a lower risk of sick leave exceeding 16 days. Having a GP with many patients reduced the risk for both genders whereas older GPs and long GP-patient relationships resulted in higher ORs for women.

\section{Predictors of return to work (RTW)}

To investigate predictors of RTW, participants with known GP variables, staying on sick leave for $>16$ days were analysed by Cox regression analysis with time to termination 


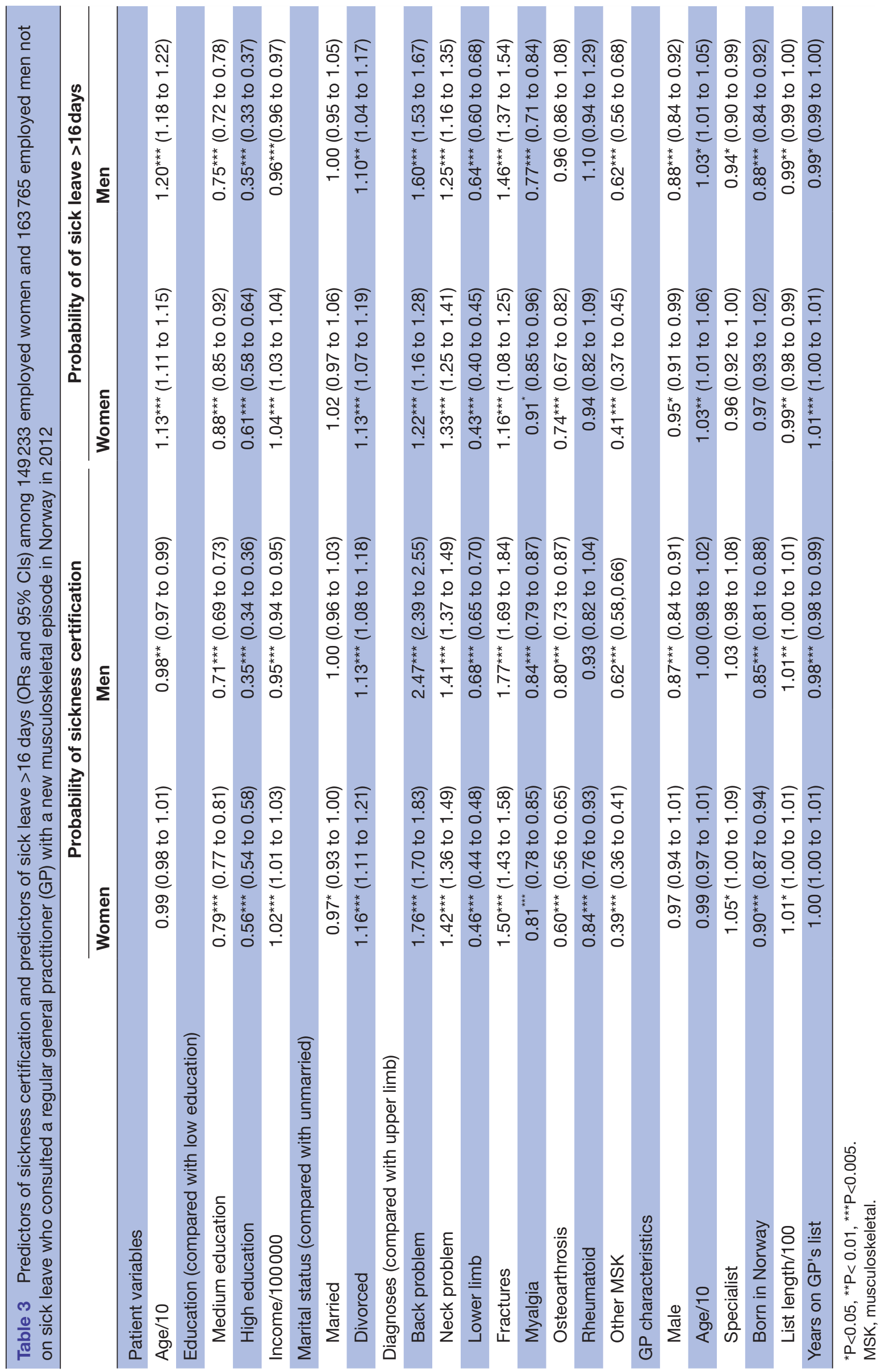


Table 4 Predictors for time to termination of sickness absence benefits during 349 days of follow-up: HR (95\% Cl), also adjusted for GP variables ( $n=15847$ women and 16049 men on sick leave for $>16$ days)

\begin{tabular}{|c|c|c|}
\hline & HR $(95 \% \mathrm{Cl})$ & HR $(95 \% \mathrm{Cl})$ \\
\hline Patient characteristics & Women & Men \\
\hline Age/10 & $0.94^{* * *}(0.93$ to 0.96$)$ & $0.90^{* * *}(0.89$ to 0.92$)$ \\
\hline \multicolumn{3}{|c|}{ Education (reference low education) } \\
\hline Medium education & $1.06^{*}(1.02$ to 1.10$)$ & 1.04 (1.00 to 1.07$)$ \\
\hline High education & $1.17^{\star \star \star}(1.11$ to 1.22$)$ & $1.20^{\star \star \star}(1.14$ to 1.26$)$ \\
\hline Income/100000 & $1.03^{\star \star \star}(1.02$ to 1.04$)$ & $1.04^{\star \star \star}(1.03$ to 1.05$)$ \\
\hline \multicolumn{3}{|c|}{ Marital status (reference never married) } \\
\hline Married & $0.93^{\star \star \star}(0.89$ to 0.96$)$ & $1.00(0.97$ to 1.04$)$ \\
\hline Divorced & $0.94^{*}(0.90$ to 0.99$)$ & 0.96 (0.91 to 1.01$)$ \\
\hline \multicolumn{3}{|l|}{ Diagnoses } \\
\hline Back problem & $1.07^{\star \star \star}(1.02$ to 1.11$)$ & $1.04^{*}(1.00$ to 1.08$)$ \\
\hline Neck problem & 0.99 (0.93 to 1.04$)$ & $0.92^{\star *}(0.86$ to 0.98$)$ \\
\hline Lower limb & 1.01 (0.96 to 1.07$)$ & 0.99 (0.94 to 1.04$)$ \\
\hline Fractures & $1.34^{\star \star *}(1.26$ to 1.42$)$ & $1.33^{* \star *}(1.27$ to 1.40$)$ \\
\hline Widespread myalgia & $0.87^{\star \star \star}(0.83$ to 0.92$)$ & $0.91^{*}(0.84$ to 0.98$)$ \\
\hline Osteoarthrosis & $0.75^{\star \star \star}(0.69$ to 0.80$)$ & $0.70^{\star \star \star}(0.64$ to 0.76$)$ \\
\hline Rheumatoid & $0.80^{\star \star \star}(0.73$ to 0.89$)$ & $0.82^{* *}(0.71$ to 0.93$)$ \\
\hline Other MSK & 1.01 (0.93 to 1.10$)$ & 0.97 (0.89 to 1.06$)$ \\
\hline
\end{tabular}

${ }^{*} \mathrm{P}<0.05,{ }^{* *} \mathrm{P}<0.01,{ }^{* * *} \mathrm{P}<0.001$.

GP, general practitioner; MSK, musculoskeletal.

of benefits as the outcome variable. In the full sample, male gender predicted a slower RTW (HR 0.97 (95\% CI 0.95 to 0.99$), \mathrm{P}<0.01)$. The results for female and male participants are shown in table 4.

High education and income predicted a more rapid RTW whereas male gender, older age and being married or divorced (only women) predicted a slower RTW. The best prognosis was for fractures/injuries and for back problems, whereas women with osteoarthrosis, rheumatoid arthritis and widespread myalgia and men with neck problems had a slower RTW. GP variables and years on the GP's list did not affect RTW and are not shown in the table.

\section{DISCUSSION}

\section{Main findings}

During 2012, 16\% of employed women and employed men in Norway consulted a RGP with a new MSK episode. The annual incidence of upper limb problems was $4 \%$ and of back pain was 3\%. Among women, 27\% received a sickness certificate compared with $28 \%$ of men. Patients with back problems were more often sickness certified ( $40 \%$ of women and $44 \%$ of men) compared with $28 \%$ of women and $24 \%$ of men with upper limb problems. After 16 days, $13 \%$ of women and $14 \%$ of men with back pain were still on sick leave, compared with $12 \%$ of women and 9\% of men with upper limb problems. During 17-365 days of follow-up, patients with back problems and fractures returned to work sooner than those with upper limb problems, and the mean length of absence was shorter for back pain than for all other groups except for fractures/injuries. In multivariate analyses, women had a slightly higher risk of sickness certification and sick leave exceeding 16 days, but RTW was slightly faster. Older age was associated with a higher risk of initial certification but a lower risk of sick leave exceeding 16 days and slower RTW. Low education increased the risk of absence due to sickness and slower RTW. Male patients with male GPs had less absence, similar to patients with GPs born in Norway (both genders). Having a GP with many patients increased the risk of sick leave exceeding 16 days. A long GP relationship decreased the risk of initial sickness certification for men but increased the risk of long-term sick leave for women. During 1 year of follow-up, GP variables had no effect on RTW.

\section{Strengths and limitations of study}

To our knowledge, this is the first nationwide incidence study in the employed population covering the full spectrum of MSK conditions. It is an inception study with clear inclusion criteria, as recommended by Steenstra $e t$ $a l^{7}$ and Wynne-Jones et $a l^{17}$ All incident MSK episodes, initial sickness certification and length of sick leave were identified. Predictors of sickness certification, sick leave $>16$ days and length of absence due to sickness were assessed. The study used all claims from publicly-funded GPs in Norway, covering $99.6 \%$ of the population. The 
study thus avoids the selection bias found in studies based on patients or GPs who volunteer to participate. The study did not use self-reports on sick leave and the sociodemographic data were of high quality. The large sample size yielded many significant findings, even when using $\mathrm{P}<0.01$. Another strength is the use of GP variables as predictors, since sickness certificates issued by GPs are normally required for absence due to sickness. However, for participants consulting locums or residents, GP variables were not known, and the statistical analyses used a 79\% sample of participants who had their index consultation with a RGP. Distribution of the explanatory variables in this sample did not differ significantly from that for all participants (table 1).

The most important limitation is the absence of information on occupation and working conditions, and the lack of patient-reported and clinical data such as level of disability, pain and psychosocial factors, ${ }^{72}$ which have been shown to predict RTW.

The incidence of clinically significant MSK problems is probably underestimated. Not all MSK consultations are with GPs; some patients go directly to specialists or physiotherapists, especially in large cities, but the extent is not known. As in Canada, ${ }^{23}$ a substantial number of consultations take place at emergency clinics (15-20\%), and some serious cases are admitted directly to hospital.

Diagnoses were the main exploratory variable in this study. Claims data only provide one diagnosis even though GPs often deal with several issues in a consultation. Patients with chronic conditions like diabetes and hypertension may be diagnosed with these even if a MSK condition is the reason for the actual consultation. This also contributes to underestimation. Multisite pain, ${ }^{29}$ an important predictor of chronicity, was not addressed either.

Diagnostic uncertainty is common in epidemiological studies of MSK disorders. Criteria and nomenclature vary. In some countries 'arthritis' is used frequently and 'injury' is used for both traumatic and non-traumatic cases. Sometimes neck and arm problems are placed in one category. The ICPC has been used by Norwegian GPs since 1992 and is also used by the National Insurance Services ${ }^{27}$ and in countries such as the Netherlands ${ }^{15} 30$ and Australia. The MSK chapter in ICPC includes 70 different codes, separating symptoms and syndromes/disease. In this study, most cases belonged to the four broad categories based on body location, like most previous studies on non-inflammatory MSK conditions, and also in back pain research, where specific pathologies are seldom used. ${ }^{26}$ This increases the GPs' diagnostic agreement. Diagnoses based on specific pathologies (inflammatory rheumatism, osteoarthrosis, and fractures) are seldom used without objective findings.

Findings from the present study should have relevance for other industrialised countries, but the external validity varies according to how health services and sickness benefit schemes are designed elsewhere.
Comparison with previous studies: incidence and prognosis of MSK disorders

Surveys of upper limb problems in the adult population have mostly assessed prevalence, ${ }^{19} 3132$ whereas incidence studies are scarce. However, a primary care study from the UK found an annual incidence of $0.9 \%$ for patients seeking care for shoulder problems among those aged $18-29$, increasing to $1.9 \%$ for those aged 60-69. ${ }^{33}$ In the Dutch national GP survey, the incidence of upper extremity disorders was $1.9 \% .^{15}$ Prognosis and recovery rates differ between studies. A Dutch study found that only $30 \%$ of individuals (all ages) were symptom-free after 1 year ${ }^{34}$ whereas a UK study found that $80 \%$ did not consult after 1 year, ${ }^{33}$ which is more similar to our findings where $9-12 \%$ of patients were on sick leave 16 days after the index consultation and only $1-2 \%$ remained on sick leave for the maximum of 1 year.

In the literature, back pain is the dominant MSK condition. ${ }^{712172135-37}$ However, in the present study and in a nationwide Canadian study from $2008^{23}$ this was not the case. A Swedish register-based study from 2009 also found a similar incidence to our study of back problems presenting in the health services. ${ }^{16}$ However, a slightly higher incidence was found for women whereas, in our study, back pain was slightly more frequent among employed men. In a meta-analysis on back pain by Wynne-Jones et al based on 34 studies including workers on sick leave for less than 4 weeks, $68 \%$ returned to work in less than 1 month, $86 \%$ in 1-6 months and $7 \%$ did not return to work when followed for more than 6 months. ${ }^{17}$ However, in an Australian cohort study of 973 incident low back pain cases where $80 \%$ were employed, $21 \%$ were sickness certified at baseline, $2.2 \%$ at 6 weeks and only $1.6 \%$ at 12 months' follow-up, which is very similar to our findings. ${ }^{6}$ Furthermore, in a recent UK study, $67 \%$ of fit note-certified absences for back problems lasted $<3$ weeks and only $12 \%$ lasted $>12$ weeks. ${ }^{4}$

\section{Comparison with previous studies: predictors of sick leave and RTW}

Previous RTW studies also mostly investigate back pain. A review by Steenstra et $a l^{7}$ found that higher age is a predictor for slow RTW, as in our study. In addition, having a specific disorder, high disability scores or social problems predicted slow RTW. Unlike our study, low education and male gender did not predict a slow RTW. Studies on sickness absence caused by upper limb problems are scarce, however. In a recent study, Armijo-Ormijo et al found small effects of sociodemographic variables on RTW compared with psychosocial measures and the DASH score (disability of arm shoulder and hand). ${ }^{28} \mathrm{~A}$ very recent systematic review investigating predictors for chronicity among patients with different MSK conditions, with RTW as one of the outcome measures, did not find evidence for older age and gender being 'generic' prognostic factors. ${ }^{38}$ 
Studies on the effect of GP variables are scarce. However, the recent study by Gabbay et $a l^{4}{ }^{46}$ based on fit note data from 68 UK general practices with all diagnoses (not only MSK conditions), assessed the effect of diagnoses, patient, GP and practice variables on length of sick leave. MSK conditions had a better prognosis than mental disorders. Female gender and younger age of patients were associated with shorter absences due to sickness. RTW was slower in deprived areas. Contrary to our study, no differences between groups of GPs were found, except that patients with GP partners (specialists) had longer absences from work than those with locums and salaried GPs, probably indicating an effect of a long doctor-patient relationship. In our study a long GP-patient relationship also increased the length of sick leave, but decreased initial certification.

Previous research has consistently shown that women have more MSK conditions than men ${ }^{39} 40$ and take more sick leave when suffering from MSK problems. ${ }^{41}$ Steenstra et al found slower RTW for women with back pain, which is also supported in a recent Spanish study. ${ }^{40}$ However, in the UK, Gabbay et al found that men had longer sick leaves. In another UK study, consultation rates for MSK conditions were similar for both genders, but men were sickness certified more often than women $(36 \%$ vs $26 \%$ ), for back pain the figures were $42 \%$ vs $32 \% .{ }^{14}$ In the present study the findings were mixed: the incidence of 'all MSK conditions' and of upper limb problems was slightly higher for women but the incidence of back pain was higher for men. After adjustments, female gender predicted more sick leave, but RTW was slightly faster.

\section{Possible explanations for different results}

Incidence data from surveys and data from healthcare registers are difficult to compare. Even studies of people of 'working age' are not similar to studies using samples of actually employed people. Also, systematic reviews ${ }^{71738}$ include studies within different settings, different design and different outcome measures, and different predictors are available. Even results concerning gender, age and educational level are not always consistent. Investigations of the role of health services and GPs in absence due to sickness is a growing research area, supplementing studies on individual and workplace-based factors. ${ }^{42-44}$

\section{Implications for clinicians and policymakers}

This study investigated challenges posed by MSK conditions for GPs, highlighting upper limb and back pain. ${ }^{45}$ Risk factors and risk groups that need special attention were identified: persons with a low education level are especially vulnerable. GPs are important stakeholders in the struggle for a more 'inclusive labour market' by helping patients to stay in work, as outlined by Black ${ }^{1}$ and Morrison. ${ }^{13}$ GPs should help their patients to improve their MSK health and avoid absence from work due to sickness, and help them to recover and return to work safely as soon as possible. ${ }^{46}$ Increased competencies are needed in MSK $^{145}$ and occupational medicine. ${ }^{13}$ During the last two decades, new strategies in tackling back pain have been implemented, focusing on activity and swift return to work. ${ }^{47}$ The present study indicates that, even though patients with back pain often need sick leave, most of them return quickly. Now upper limb problems need more attention, ${ }^{32}$ since many cases develop into chronicity. New treatments for shoulder problems and epicondylitis $^{48-50}$ are currently being developed in primary care ${ }^{45}$ Since MSK disorders are often work-related, ${ }^{51} 52$ prevention in the workplaces is important and occupational health services should play a crucial role. GPs need increased knowledge of their patients' workplace conditions, better skills in multidisciplinary cooperation and improved cooperation with occupational health services. Findings from this study indicate that GPs from abroad might need special education about the Norwegian worklife and work environment legislations. Policymakers should improve GPs' participation in the 'Inclusive worklife campaign' currently established by the Government, together with the employers' and workers' organisations.

\section{Unanswered questions and future research}

The burden of MSK conditions other than back pain in the labour force, their role in sick leave and RTW and better treatment need more attention in research. The present findings need testing in future large-scale epidemiological studies in other countries.

Contributors SG, THH, KM and $\emptyset \mathrm{H}$ participated in the planning of the study, data analysis, writing and final approval of the manuscript.

Funding The study is funded by the Norwegian Research Council (Norges Forskningsråd) grant number 237991.

Competing interests None declared.

Patient consent Not required.

Provenance and peer review Not commissioned; externally peer reviewed.

Data sharing statement Data from Norwegian public registers is held by Statistics Norway and owners of the registers, and anonymous data are available by request for research after permission from the Data Inspectorate.

Open Access This is an Open Access article distributed in accordance with the Creative Commons Attribution Non Commercial (CC BY-NC 4.0) license, which permits others to distribute, remix, adapt, build upon this work non-commercially, and license their derivative works on different terms, provided the original work is properly cited and the use is non-commercial. See: http://creativecommons.org/ licenses/by-nc/4.0/

(c) Article author(s) (or their employer(s) unless otherwise stated in the text of the article) 2018. All rights reserved. No commercial use is permitted unless otherwise expressly granted.

\section{REFERENCES}

1. Black CM. Sickness absence and musculoskeletal disorders. Rheumatology 2012;51:204-5.

2. Bevan S, Quadrello T, McGee R, et al. Fit for work? Musculoskeletal disorders in the European workforce. London: The Work Foundation, 2009.

3. Bevan S. Economic impact of musculoskeletal disorders (MSDs) on work in Europe. Best Pract Res Clin Rheumatol 2015;29:356-73.

4. Gabbay M, Shiels C, Hillage J. Factors associated with the length of fit note-certified sickness episodes in the UK. Occup Environ Med 2015;72:467-75.

5. NAV https://www.nav.no/no/NAV+og+samfunn/Statistikk/ Sykefravar+-+statistikk/Tabeller/legemeldte-sykefrav\%C3\% A6rstilfeller-4-kv-2007-2016.diagnose-og-kj\%C3\%B8nn.antall 
6. Henschke N, Maher CG, Refshauge KM, et al. Prognosis in patients with recent onset low back pain in Australian primary care: inception cohort study. BMJ 2008;337:a171.

7. Steenstra IA, Verbeek JH, Heymans MW, et al. Prognostic factors for duration of sick leave in patients sick listed with acute low back pain: a systematic review of the literature. Occup Environ Med 2005;62:851-60.

8. Jansson C, Alexanderson K. Sickness absence due to musculoskeletal diagnoses and risk of diagnosis-specific disability pension: a nationwide Swedish prospective cohort study. Pain 2013;154:933-41.

9. Gjesdal S, Bratberg E, Maeland JG. Musculoskeletal impairments in the Norwegian working population: the prognostic role of diagnoses and socioeconomic status: a prospective study of sickness absence and transition to disability pension. Spine 2009;34:1519-25.

10. Lambeek LC, van Tulder MW, Swinkels IC, et al. The trend in total cost of back pain in The Netherlands in the period 2002 to 2007. Spine 2011;36:1050-8.

11. Winde LD, Alexanderson K, Carlsen B, et al. General practitioners' experiences with sickness certification: a comparison of survey data from Sweden and Norway. BMC Fam Pract 2012;13:10.

12. Lewis M, Wynne-Jones G, Barton P, et al. Should general practitioners issue a sick certificate to employees who consult for low back pain in primary care? J Occup Rehabil 2015;25:577-88.

13. Morrison J. The role of the GP in keeping people in work. Occup Med 2011;61:74-5.

14. Wynne-Jones G, Mallen CD, Dunn KM. Sickness certification for musculoskeletal conditions. Clin Rheumatol 2010;29:573-4.

15. Bot SD, van der Waal JM, Terwee CB, et al. Incidence and prevalence of complaints of the neck and upper extremity in general practice. Ann Rheum Dis 2005;64:118-23.

16. Jöud A, Petersson IF, Englund M. Low back pain - epidemiology of consultations. Arthritis Care Res 2012;64:n/a-8.

17. Wynne-Jones G, Cowen J, Jordan JL, et al. Absence from work and return to work in people with back pain: a systematic review and meta-analysis. Occup Environ Med 2014;71:448-56.

18. Henschke N, Maher CG, Refshauge KM, et al. Characteristics of patients with acute low back pain presenting to primary care in Australia. Clin J Pain 2009;25:5-11.

19. Walker-Bone K, Palmer KT, Reading I, et al. Prevalence and impact of musculoskeletal disorders of the upper limb in the general population. Arthritis Rheum 2004:51:642-51.

20. Picavet HS, Schouten JS. Musculoskeletal pain in the Netherlands: prevalences, consequences and risk groups, the DMC(3)-study. Pain 2003:102:167-78.

21. Hoy D, Bain C, Williams G, et al. A systematic review of the global prevalence of low back pain. Arthritis Rheum 2012;64:2028-37.

22. Foster NE, Hartvigsen J, Croft PR. Taking responsibility for the early assessment and treatment of patients with musculoskeletal pain: a review and critical analysis. Arthritis Res Ther 2012;14:205.

23. MacKay C, Canizares M, Davis A, et al. Health care utilization for musculoskeletal disorders. Arthritis Care Res 2010;62:NA-9.

24. Jordan K, Clarke AM, Symmons DP, et al. Measuring disease prevalence: a comparison of musculoskeletal disease using four general practice consultation databases. Br J Gen Pract 2007:57:7-14.

25. van der Waal JM, Bot SD, Terwee CB, et al. The incidences of and consultation rate for lower extremity complaints in general practice. Ann Rheum Dis 2006;65:809-15.

26. Jordan KP, Kadam UT, Hayward R, et al. Annual consultation prevalence of regional musculoskeletal problems in primary care: an observational study. BMC Musculoskelet Disord 2010;11:144.

27. Brage S, Bentsen BG, Bjerkedal T, et al. ICPC as a standard classification in Norway. Fam Pract 1996;13:391-6.

28. Armijo-Olivo S, Woodhouse LJ, Steenstra IA, et al. Predictive value of the DASH tool for predicting return to work of injured workers with musculoskeletal disorders of the upper extremity. Occup Environ Med 2016;73:807-15.

29. Miranda H, Kaila-Kangas L, Heliövaara M, et al. Musculoskeletal pain at multiple sites and its effects on work ability in a general working population. Occup Environ Med 2010;67:449-55.

30. Westert GP, Schellevis FG, de Bakker DH, et al. Monitoring health inequalities through general practice: the second dutch national survey of general practice. Eur J Public Health 2005;15:59-65.
31. Picavet HS, Hazes JM. Prevalence of self reported musculoskeletal diseases is high. Ann Rheum Dis 2003;62:644-50.

32. Linaker $\mathrm{CH}$, Walker-Bone K. Shoulder disorders and occupation. Best Pract Res Clin Rheumatol 2015;29:405-23.

33. Linsell L, Dawson J, Zondervan K, et al. Prevalence and incidence of adults consulting for shoulder conditions in UK primary care; patterns of diagnosis and referral. Rheumatology 2006;45:215-21.

34. Bot SD, van der Waal JM, Terwee CB, et al. Predictors of outcome in neck and shoulder symptoms: a cohort study in general practice. Spine 2005;30:E459-70.

35. Global Burden of Disease Study 2013 Collaborators. Global, regional, and national incidence, prevalence, and years lived with disability for 301 acute and chronic diseases and injuries in 188 countries, 19902013: a systematic analysis for the global burden of disease study 2013. Lancet 2015;386:743-800.

36. Shiels C, Hillage J, Pollard E, et al. An evaluation of the statement of fitness for work (fit note): quantitative survey of fit notes. DWP research report. London: The Stationery Office, 2013.

37. Hoy D, March L, Brooks P, et al. The global burden of low back pain: estimates from the Global Burden of Disease 2010 study. Ann Rheum Dis 2014;73:968-74.

38. Artus M, Campbell P, Mallen CD, et al. Generic prognostic factors for musculoskeletal pain in primary care: a systematic review. BMJ Open 2017;7:e012901.

39. Wijnhoven HA, de Vet HC, Picavet HS. Prevalence of musculoskeletal disorders is systematically higher in women than in men. Clin J Pain 2006;22:717-24.

40. Arcas MM, Delclos GL, Torá-Rocamora I, et al. Gender differences in the duration of non-work-related sickness absence episodes due to musculoskeletal disorders. J Epidemiol Community Health 2016;70:1065-73.

41. Mastekaasa A. The gender gap in sickness absence: longterm trends in eight European countries. Eur J Public Health 2014;24:656-62.

42. Money A, Hann M, Turner S, et al. The influence of prior training on GPs' attitudes to sickness absence certification post-fit note. Prim Health Care Res Dev 2015;16:528-39.

43. Aakvik $A$, Holmås TH, Kamrul Islam M. Does variation in general practitioner (GP) practice matter for the length of sick leave? A multilevel analysis based on Norwegian GP-patient data. Soc Sci Med 2010;70:1590-8.

44. Coole C, Watson PJ, Drummond A. Work problems due to low back pain: what do GPs do? A questionnaire survey. Fam Pract 2010;27:31-7.

45. Helliwell T, Mallen C, Peat G, et al. Research into practice: improving musculoskeletal care in general practice. $\mathrm{Br} J$ Gen Pract 2014;64:372-4.

46. Hoy DG, Smith E, Cross M, et al. Reflecting on the global burden of musculoskeletal conditions: lessons learnt from the Global Burden of Disease 2010 study and the next steps forward. Ann Rheum Dis 2015;74:4-7.

47. Indahl A. Low back pain: diagnosis, treatment, and prognosis. Scand J Rheumatol 2004:33:199-209.

48. Hill JC, Whitehurst DG, Lewis M, et al. Comparison of stratified primary care management for low back pain with current best practice (STarT Back): a randomised controlled trial. Lancet 2011;378:1560-71

49. Lewis M, Chesterton LS, Sim J, et al. An economic evaluation of TENS in addition to usual primary care management for the treatment of tennis elbow: results from the TATE randomized controlled trial. PLoS One 2015;10:e0135460.

50. Sharma SP, Bærheim A, Moe-Nilssen R, et al. Adhesive capsulitis of the shoulder, treatment with corticosteroid, corticosteroid with distension or treatment-as-usual; a randomised controlled trial in primary care. BMC Musculoskelet Disord 2016;17:232.

51. Mehlum IS, Kristensen P, Kjuus H, et al. Are occupational factors important determinants of socioeconomic inequalities in musculoskeletal pain? Scand J Work Environ Health 2008;34:250-9.

52. de Cássia Pereira Fernandes R, da Silva Pataro SM, de Carvalho $\mathrm{RB}$, et al. The concurrence of musculoskeletal pain and associated work-related factors: a cross sectional study. BMC Public Health 2016;16:628. 